\title{
Mångkulturella klassrum som kunskapskälla
}

\section{Av Annette Årheim}

\author{
Länk till presentation av Annette Årheim
}

När jag påbörjade min forskning om litteraturdidaktik i dagens mångkulturella klassrum fanns där en och annan, till synes självskriven, hypotes i mitt huvud. Mitt intresse för detta forskningsfält har sin grund i en föreställning om det komplexa i att bedriva en svenskundervisning, som i konkurrens med massmediers konfrontations- och konfliktperspektiv skall leda till att eleven anammar en positiv syn på det mångkulturella samhället.[1] Men när jag i början närmar mig mina informanter, ungdomar som går sin första termin på gymnasiet, tittar de oförstående på mig när jag ställer frågor som handlar om integrationsproblem och umgänge över kulturella gränser. En tjej kontrar med: "Det där tror jag är ett vuxenproblem." En anledning till flickans reflexion kan vara att vi som tillhör en äldre generation ofta talar i termer av att samhället blivit mångkulturellt och att massmedieutbudet blivit oöverskådligt. En sådan beskrivning ter sig förmodligen främmande för de ungdomar jag för närvarande intervjuar, eftersom de är uppväxta i ett mångkulturellt och medialiserat samhälle och inte kan relatera till en annan verklighet. Under 1960- och 70-talen präglades precis som idag massmedier av en bild där västvärlden och i synnerhet Sverige utgjorde skapelsens slutpunkt. En avgörande skillnad om man ser till slutprodukten - mediebilden av invandraren - är att då när landet Sverige var i skriande behov av arbetskraft till industrin, fann man inga skäl att ifrågasätta dessa arbetskraftsinvandrares vilja att bli goda svenskar.

Även om man inom skolans ramar tycks ha lyckats förmedla nödvändigheten av tolerans över kulturgränser, framkommer i mina samtal med ungdomar djupt rotade fördomar och myter mot våra invandrade svenskar, en tendens som kan spåras ända tillbaka till 1700talet.[2] Därför vill jag här behandla Mångkulturella klassrum som kunskapskälla ur två olika perspektiv. Först tänker jag helt kort beskriva varför dagens mångkulturella klassrum är en viktig kunskapskälla för forskning om svenskämnet i skolan. Artikelns huvudsakliga del kommer dock att behandla svenskämnets förutsättningar att utveckla elevernas demokratiska kompetens i en mångkulturell och medialiserad verklighet.

\section{Ideologier, myter och skönlitteratur}

Skolans undervisning styrs precis som alla andra praktiker av de ideologier som är förhärskande i det omgivande samhället. En ideologi kan beskrivas som ett sätt att varsebli verkligheten och samhället, där man utgår från att vissa idéer till sin natur är sanna, medan andra är självklart förvanskade och falska.[3] Det som håller en viss ideologis naturlighet vid liv är i sin tur myter som gynnar enbart ett sätt att tänka, samtidigt som de eliminerar alternativa synsätt.[4] De ideologier som ligger till grund för verksamheten på våra skolor idag framhäver alltså det naturliga i att skolan ska fostra eleverna till en positiv syn på det mångkulturella - att utbilda toleranta, ansvarstagande och solidariska medborgare som har respekt för varandras olikheter. Skolundervisningen ska leda till en "gemensam värdegrund" för såväl infödda som invandrade svenskar. Detta föreskrivs klart i styrdokument på olika nivåer, från Skollagen ner till det enskilda ämnets kursplaner. Man kan dock se det som en seglivad myt att vi bäst bygger en sådan värdegrund genom att kulturarvet förmedlas till och förankras hos eleverna.

Det odefinierade kulturarvsbegreppet har lett till bekymmer för svensklärare. Vad betyder egentligen kultur? Skolan har traditionellt sett som sin uppgift att skydda barn och 
ungdomar från populärkulturens demoraliserande berättelser.[5] Högkulturen och de skönlitterära klassikerna har haft sin givna plats som motvikt till ungdomarnas egen kultur en strategi som blivit allt mer uddlös i ett snabbt växande medieutbud. Och vad betyder egentligen kulturarvet, i styrdokumenten uttryckt i singularis, när man står framför en klass där flera etniciteter finns representerade? Ska alla ha läst Almqvist, Strindberg och någon svensk arbetarförfattare eller innebär förvaltandet av kulturarvet att klassen bör ta del av exempelvis bosniska, libanesiska eller somaliska författares verk?

Människor är nu lyckligtvis inte slavar under de myter som bär upp ideologier. När situationen blir komplex, som i svenskundervisningen i mångkulturella klassrum, öppnas möjligheter för kontraproduktiva myter - alltså myter som ifrågasätter det förgivet tagna. Sådana kontramyter har resulterat i att klassikerna idag stuvas om i skolornas bokförråd för att göra plats för klassuppsättningar av de tidigare ratade kioskvältarna. Med dagens stora utbud av bildmedier gäller det att få ungdomar att läsa någonting överhuvudtaget. Är detta en positiv utveckling? Det är svårt att svara entydigt ja eller nej. Klart står dock att detta oreflekterade förhållningssätt till skönlitteraturens naturliga överlägsenhet - läsning till varje pris - bör problematiseras och ägnas uppmärksamhet i fortsatt forskning.

\section{Den tysta mytreproduktionen}

När myter om främmande kulturer skanderas på gator och torg av rasistiska grupper så reagerar de flesta människor omedelbart med avsky. Fördomar avslöjas direkt, man känner behov av att markera avstånd och vägen ligger då öppen för produktion av kontramyter. Ett större problem utgör däremot de myter om främmande kulturer som verkar i det tysta och som manifesteras genom det som inte sägs. I det följande ska jag presentera ett konkret exempel hämtat ur mina forskningsresultat. Med exemplet vill jag visa på några didaktiska konsekvenser av att populärlitteraturen har fått en given plats i dagens mångkulturella klassrum.

Berättelser har stor makt över konstruktionen av såväl andras egenskaper som den egna identiteten och i detta faktum ligger, menar jag, litteraturundervisningens stora potential.[6] Men här finns också fällor som Ylva Brune, med hänvisning till Thomas Hylland Eriksen, pekar på i sin studie av mediebilden av invandrare och flyktingar: "Ibland sägs det att islam och muslimer har fått fylla fiendetomrummet efter Sovjets och Östblockets fall, och det är kanske riktigt. Men varför just denna fiende, när det finns så många hot att välja på? För att kunna diskutera frågan behöver man kanske fördjupa sig mer i hur svensk/västeuropeisk identitetsbildning sker, än i vad islam och muslimer är."[7]

En författare som idag runt om på våra skolor används som dragplåster för att få ungdomar att läsa är Liza Marklund. När jag intervjuade förstaterminselever på gymnasiet, var det slående hur många som uppgav att just dokumentärromanen Gömda (1995) var den bok som gjort starkast intryck på dem av det de läst.[8] Att just denna roman av Marklund ofta läses redan på högstadiet fick jag nyligen bekräftat vid ett seminarium med tolv lärare, verksamma på olika orter mellan Ystad och Hudiksvall.

Redan på titelsidan till Liza Marklunds Gömda får man veta att det handlar om "en sann historia" och på ett försättsblad även att Marklund haft en medförfattare vid namn Maria Eriksson: "Mia berättade, jag skrev", skriver Marklund i förordet och anledningen till att Mia vill delge läsaren sin berättelse sägs vara att "familjen håller på att gå under" på grund av "samhällets oförmåga att handskas med problem som förföljelse och kvinnovåld". Marklunds dokumentära roman beskriver också detta angelägna problem och berättelsen gav upphov till debatt ända in i Sveriges riksdag.[9] Vad som inte sägs vare sig i försättsblad eller baksidestext är att parallellt med den beskrivna historien, levereras också berättelsen om den ologiske, orationelle och patriarkaliske invandrarmannen. Han som i skuggan av sin traditionella kultur och religion förtrycker sin familj och över tid blivit bitter mot ett Sverige där hans auktoritet inte respekteras.[10] 


\section{Journalisten Marklund i klassrummen}

Handlingen i Gömda sträcker sig från 1980-talets mitt och tio år framåt i tiden i en svensk småstad. När vi först får träffa den unga huvudkaraktären Mia arbetar hon som banktjänsteman men är också aktiv inom ett nätverk som undsätter utvisningshotade flyktingar. Hon framställs som en empatisk och självuppoffrande person när hon hjälper en sydamerikansk familj att gömma sig undan myndigheterna. Liksom flera av sina väninnor förälskar sig Mia i en mörkögd, uppvaktande man från Libanon som bor på stadens flyktingförläggning. Snart är hon oplanerat gravid, och den tidigare så trevlige libanesen visar allt oftare förtryckande och våldsamma sidor när han sporadiskt dyker upp i den gemensamma lägenheten. En dag när Mia sitter och ammar det nyfödda flickebarnet dyker han upp med "brinnande ögon". Han begär att få visa barnet för sina kompisar och strax är männen i full gång med en makaber lek där de kastar spädbarnet mellan sig:

Han kastade babyn i en hög båge över rummet. Jag kände inte igen rösten som skrek, men den var min.

- Åh, Guud!

Den lilla kroppen flög genom rummet. Hon skrek rätt ut. Den medfödda omfamningsreflexen fick hennes kropp att röra sig spasmiskt i luften. Ali fångade henne, fumlade och var nära att tappa henne. Han skrattade.

- Snälla, snälla, skrek jag panikslaget, tårarna började rinna. Snälla, snälla.

- Vem vill? Ropade Ali och höjde flickan högt ovanför sitt huvud.

[---]

- Catch! ropade han och kastade iväg flickan som om hon varit en mjölpåse (s. 116 f.).

Mias tio år långa mardröm exemplifieras med citatet ovan och "han", som läsaren aldrig får veta namnet på, ger Mia och dottern berättelsen igenom epiteten "hora" och "horunge". När Mia bryter sig ur förhållandet, träffar en ny förstående, varm och svensk man som hon får ytterligare ett barn med intensifieras terrorn i form av förföljelser, vandalism och mordhot. Mia och hennes nya familj tvingas leva gömda, precis som den flyktingfamilj Mia hjälpt i romanens början. De får fly från den ena platsen till den andra och tvingas slutligen lämna Sverige och börja om i en annan världsdel under ny identitet. "Han" däremot lever enligt epilogen trots åtskilliga brott, domar och rättspsykiatriska undersökningar kvar i Mias hemstad, där han funnit en ny kvinna att misshandla och förtrycka.

I linje med det vi fătt veta om romanens tillkomst är den skriven i jag-form med Mia som berättare historien igenom. Läsaren upplever besvikelsen, skräcken och vanmakten genom hennes ögon och Marklund har på detta sätt försäkrat sig om läsarens lojalitet med berättaren. Den ensidiga fokaliseringen i kombination med greppet att aldrig ge den libanesiske mannen ett namn omintetgör läsarens möjlighet att överhuvud se "honom" som en människa av kött och blod.

Det är intressant att i sammanhanget uppmärksamma att Liza Marklund har ett förflutet som journalist och att Gömda är hennes debutroman. Ylva Brune visar på nyhetsjournalistikens utveckling gällande rapporteringen kring invandringen och hon tar sin utgångspunkt i 1970-talets positiva mediebild av den första utomeuropeiska gruppen som sökte sig till Sverige, bestående av kristna turkar och libaneser.[11] Vid 1980-talets mitt när handlingen i Gömda utspelar sig har västerlandets omhuldade framgångsmyt fått sig en knäck och nyhetsjournalistiken ändrar därmed karaktär. Integrationsprocessen visade sig komplicerad. Länstidningen Södertälje, som 1976 glatt utropar att "Generaliserat kan man ju säga att assyrierna kommer från medeltiden till ett modernt samhälle", upplever under 1980-talet hur dessa flyktingar liksom vill klumpa ihop sig kring Södertälje och den kristna ortodoxa församling som finns där. Flyktinginvandringen fördubblades 1984-85; de flesta kom från Iran, Irak och Libanon. De definieras som lycksökare och lyxlirare av en hårt belastad polis och det finns inte längre från journalistkåren några "försök att porträttera flyktingarnas personliga eller politiska bakgrund i hemlandet".[12]

Undersökningar har visat att svenskarnas attityder till invandringspolitiken än idag är ambivalenta. Samtidigt som det finns en uttalad vilja att minska invandringen kritiserar 
man den inhumana flyktingpolitiken. Kritiken riktar sig främst mot behandlingen av enskilda flyktingar, då medierna framställt dem som människor med namn, ansikten och känslor.[13] Berättelser har alltså bevisligen potential att få människor att solidarisera sig med individer över kulturgränser. Men i fallet Gömda är den enda bild vi får av den asylsökande mannen en våldsam och manipulativ personlighet med total avsaknad av empatisk förmåga samt två svarta och samtidigt brinnande ögon. Hur han själv har upplevt sitt förhållande med Mia får läsaren aldrig reda på. "Han", ska det visa sig, har också ljugit om sitt ursprung för Mia och endast använt islam som en förevändning att förtrycka henne. I själva verket är han kristen och har medverkat i massakrerna i Sabra och Shatila.

\section{Didaktiska konsekvenser - är innehållet underordnat mediet?}

En ideologikritisk analys av Marklunds Gömda skulle lätt ta en hel avhandling i anspråk. Här nöjer jag mig dock med att genom exemplet ovan konstatera att alla de myter som ligger till grund för främlingsfientlighet bekräftas i texten genom det som inte skrivs. Konsekvenserna av detta och den enskilde tonåringens hantering av den känsloladdade berättelsen beror på hur läsupplevelsen bearbetas. Somliga elever, har jag erfarit, finner i Marklunds roman bekräftelse på mediebilden av invandraren som ett problem och hot mot den svenska normaliteten. Om inte dessa elever fångas upp och erbjuds motbilder är risken överhängande att jakten på ytterligare bekräftelse på de egna fördomarna fortsätter - man söker ytterligare litteratur med samma teman och samma kraft att beröra.

Medan engagerade lärare idag lägger pannan i djupa veck över det vidgade textbegreppet och över vilka filmer som egentligen kan anses etiskt och estetiskt försvarbara att visa i klassrummet, kan man konstatera att i litteraturen och litteraturvalen är reflexionen mindre utpräglad. Paradoxalt nog värnas fortfarande filmcensuren både på biografer och i skolor, medan gränsen mellan barn- och vuxenlitteratur blivit allt mer diffus.[14] Ändå är läsning något som oftast sker i ensamhet. Upplevelserna av läsningen är därtill något som ungdomar sällan på eget initiativ talar med varandra om. Filmtittande däremot visar sig i min studie vara en social aktivitet. Ungdomar hyr oftast videofilmer för att se på tillsammans med kompisar eller familjen och diskussioner förekommer ofta både under tittandet och efteråt.

Och ändå, att över huvud taget läsa är mottot för dagen och i denna kamp är innehållet underordnat mediet; ändamålet helgar medlen! Lärarens roll, menar jag, är inte bara att se till att eleverna läser, utan också vad de läser - åtminstone om vi skriver under på att skönlitteraturen positivt utvecklar förmåga till inlevelse och empati för främmande kulturers tankesätt. Det kan tyckas som en orimlig uppgift att hålla reda på den enskilde elevens bokval, reception och attitydförändring, men jag är övertygad om att vi måste finna vägar för detta. Viktigast förefaller det mig att svenskläraren får utbildning i, och utrymme inom sin tjänst, att göra ideologikritiska läsningar av den litteratur som erbjuds eleverna. Först då kan vi i klassens litteratursamtal blottlägga de parallella, betydelsebärande och tysta berättelserna i romaner som Gömda, avslöja en och annan myt och bana väg för kontramyter.

I mitt avhandlingsarbete intresserar jag mig för berättelsens betydelse i mångkulturella klassrum och de attityder och kompetenser som där utvecklas. Man får lätt uppfattningen att attityder skulle ha spelat ut sin roll i det postmoderna samhället - att man idag vänder kappan efter vinden och anammar den attityd som för tillfället gagnar en personligen. Men i gymnasiekommitténs slutbetänkande inför den nya gymnasiereformen utpekas just "attityder - att vilja handla och ta ansvar" som en av kompetensbegreppets viktigaste bestämningar.[15] Det handlar här såväl om individens utveckling, som om utveckling av eleven som medborgare i ett demokratiskt och mångkulturellt samhälle.

Att värderingar förblir ganska stabila genom generationer visar många undersökningar. I min egen studie kan jag också se att värderingarna är tämligen homogena oavsett etnicitet. Detta skulle kunna tyda på att vi redan har en slags gemensam värdegrund och att de mångkulturella problemen i samhället till stora delar är en fråga om attityder. Att attityder 
är mera flyktiga och svårstuderade än värderingar gör dem inte mindre betydelsefulla i mötet med det annorlunda. Därför ser jag det som angeläget att forska vidare om fenomenet.

(C) Annette Årheim

\section{Referenser}

Barthes, Roland, Mythologies, London 1973.

Bignell, Jonathan, Media Semiotics, Manchester \& New York 1997.

Brune, Ylva, Stereotyper i förvandling. Svensk nyhetsjournalistik om invandrare och flyktingar, MENA-projektet UD Stockholm, 2000:11.

Brune, Ylva, "'Invandrare' i mediearkivets typgalleri", Maktens (o)lika förklädnader, (red.) de los Reyes m.fl., Stockholm 2002, s. 150 - 181.

Gymnasiekommittén, Åtta vägar till kunskap, Stockholm 2002.

Holmberg, Åke, Världen bortom Västerlandet II, Acta, Göteborg 1994.

Kampp, Bodil, Barnet og den voksne i det børnelittercere rum, Köpenhamn 2002.

Kearney, Richard, On Stories, London 2002

Marklund, Liza, Gömda, Stockholm 2000

Nussbaum, Martha C., Cultivating Humanity. A Classical Defense of Liberal Education, Harvard College 1997.

Persson, Magnus, "Populärkultur i skolan: Traditioner och perspektiv" ur Populärkulturen och skolan, (red.) M. Persson, Lund 2000, s. 15 - 101

Tigervall, Catharina, "'Invandrarfilm' och eurocentriska myter", Häften för kritiska studier 36, 2003:1

Örnebring, Henrik, TV-parlamentet. Debattprogram i svensk TV 1956-1996, Göteborg 2001.

[1] Att mediebilden av samma fenomen gått från konsensus- till konfliktperspektiv påvisas exempelvis i Henrik Örnebrings avhandling TV-parlamentet. Debattprogram i svensk TV 1956 - 1996, Göteborg, 2001, samt i Ylva Brunes delstudie för utrikesdepartementets MENA-projekt, Stereotyper i förvandling. Svensk nyhetsjournalistik om invandrare och flyktingar, UD Stockholm, 2000:11.

[2] Åke Holmberg presenterar en typologi för svenska fördomsmönster i Världen bortom Västerlandet II, Acta, Göteborg 1994. Den första typen av fördomar som fått benämningen pistocentriska handlar om hur "vi-gruppen konstitueras av religiös gemenskap: kristna, lutheraner kontra muslimer och hedningar i Asien och Afrika" (1994: 23).

[3] Jonathan Bignell, Media Semiotics, Manchester \& New York, 1997, s. 25.

[4] Roland Barthes, Mythologies, London, 1973.

[5] Magnus Persson, "Populärkultur i skolan: Traditioner och perspektiv" ur Populärkulturen och skolan, (red.) M. Persson, Lund 2000, s. 15 - 101.

[6] Se exempelvis Richard Kearney, On Stories, London 2002 och Martha C. Nussbaum, Cultivating Humanity. A Classical Defense of Liberal Education, Harvard College 1997. [7] Ylva Brune, Stereotyper i förvandling. Svensk nyhetsjournalistik om invandrare och flyktingar, UD Stockholm 11:2000, s. 22.

[8] Maria Eriksson \& Liza, Marklund, Gömda, Stockholm 1995. I den kommande analysen använder jag utgåvan från 2000 .

[9] Intressant att notera i sammanhanget är att flyktingpolitiken stramades åt i Sverige vid 1980-talets slut.

[10] Hur denna stereotypa bild av invandrarmannen vuxit fram och traderats av massmedier beskrivs av Ylva Brune i "'Invandrare' i mediearkivets typgalleri", Maktens (o)lika förklädnader, (red.) de los Reyes m.fl., Stockholm 2002, s. 150 - 181.

[11] Brune, (2000), s. 10f.

[12] Ibid. s. 14f.

[13] Catharina Tigervall, "'Invandrarfilm' och eurocentriska myter", Häften för kritiska studier 36 (2003:1), s. 46.

[14] Bodil Kampp, Barnet og den voksne i det børnelitterære rum, Köpenhamn, 2002. 
[15] Gymnasiekommittén, Åtta vägar till kunskap, Stockholm, 2002, s. 95. 